\title{
Espécies novas de Dendroblatta do Brasil (Blattaria, Blattellidae)
}

\author{
Sonia Maria Lopes \& Edivar Heeren de Oliveira
}

Departamento de Entomologia, Museu Nacional, Universidade Federal do Rio de Janeiro, Quinta da Boa Vista, São Cristóvão, 20940-040 Rio de Janeiro, Brasil. (sonialf@acd.ufrj.br)

\begin{abstract}
New species of Dendroblatta from Brazil (Blattaria, Blattellidae). New species of Dendroblatta Rehn, 1916 are described: D. matogrossensis from Mato Grosso and D. mineira from Minas Gerais. The male genitalia are illustrated.
\end{abstract}

KEYWORDS. Dendroblatta, taxonomy, new species, Neotropical.

RESUMO. Espécies novas de Dendroblatta Rehn, 1916 são descritas: D. matogrossensis de Mato Grosso e D. mineira de Minas Gerais. As genitálias dos machos são ilustradas.

PALAVRAS-CHAVE. Dendroblatta, taxonomia, espécies novas, Neotropical.

ReHn (1916) descreveu Dendroblatta, tendo por base a espécie-tipo $D$. sobrina. Atualmente com doze espécies, o gênero ocorre na América Central (Nicarágua, Costa Rica e Panamá) e na América do Sul (Trinidad, Venezuela, Guiana, Suriname, Guiana Francesa, Colômbia, Peru e no Brasil nos Estados do Amapá, Amazonas, Pará, Acre, Rondônia, Bahia e Rio de Janeiro).

\section{MATERIAL E MÉTODOS}

Os espécimes foram analisados morfologicamente de acordo com LoPES \& Oliveira (2000) e depositados no Museu Nacional, Universidade Federal do Rio de Janeiro (MNRJ). As placas e peças genitais internas foram acondicionadas em "microvials", contendo glicerina e devidamente fixados junto ao respectivo exemplar, montado em alfinete entomológico, técnica desenvolvida por GURNEY et al. (1964). A classificação taxonômica seguiu McКітTRIск (1964).

\section{Dendroblatta matogrossensis sp. nov.}

(Figs. 1, 3-5, 8, 10, 14)

Coloração geral castanho-clara, brilhosa (Fig. 14). Coloração castanho-escura nas manchas da cabeça (Fig. 1), no pronoto em uma estreita área centro-basal, disco central com o entorno apical e manchas centrais (Fig. 3), na tégmina, tronco inicial de todas as nervuras e parte do campo anal e do campo discoidal, nas bases de inserção dos espinhos nas pernas. Pulvilos esbranquiçados.

Medidas em mm, holótipo $\sigma^{\top}$. Comprimento total, 20,0; comprimento do pronoto, 4,0; largura do pronoto, 6,0 ; comprimento da tégmina, 18,0; largura da tégmina, 6,0 .

Cabeça triangular; vértice pouco exposto; espaço interocular estreito, cerca de um quarto da distância entre as bases das inserções antenais; ocelos bem definidos. Antenas longas, tomentosas, ultrapassam o ápice do abdome. Palpos maxilares desenvolvidos, primeiro e segundo artículos curtos, terceiro artículo mais longo que o quarto, quinto artículo dilatado, tomentoso e pouco mais curto que o terceiro.

Pronoto (Fig. 3) convexo, oval e transverso, margens apical e basal retas, abas laterais amplas, com contorno arredondado. Tégminas desenvolvidas, longas, ultrapassam o ápice dos cercos; campo marginal levemente côncavo e bem marcado; campo escapular estreito e alongado, campo discoidal amplo, campo anal curto. Pernas desenvolvidas e espinhosas. Fêmur I na face ântero-ventral com uma série de seis ou sete espinhos robustos, da base até a região mediana, seguida até o ápice de outra série de espinhos pequenos e muito próximos, mais dois apicais desenvolvidos, sendo o último o dobro do anterior. Fêmures II e III com faces antero- e póstero-ventrais semelhantes, apresentando espinhos robustos e espaçados em toda sua extensão, com um apical maior. Pulvilos apenas no quarto artículo tarsal, arólio pouco desenvolvido, unhas simétricas e simples.

Abdome sem modificação tergal. Placa supra-anal ciliada, pronunciada entre os cercos, com marcante reentrância mediana; cercos desenvolvidos e ciliados (Fig. 4). Placa subgenital assimétrica, ciliada, com projeções laterais desenvolvidas e arredondadas; estilos alargados na região mediana da placa, arredondados e semelhantes (Fig. 10). Esclerito mediano (L2vm) simples e com ápice (L2d) em forma de foice afilada (Fig. 5). Falômero esquerdo (L1) em forma de Y invertido, com uma das pontas arredondada e a outra afilada e a região central esclerotinizada (Fig. 8).

Material-tipo. Holótipo ơ, BRASIL, Mato Grosso: Sinop, X.1975, Roppa \& Alvarenga col.

Etimologia. O nome é alusivo ao estado brasileiro onde o material foi coletado.

Diagnose. Dendroblatta matogrossensis sp. nov. distingue-se das demais espécies do gênero pela configuração da placa subgenital e pelo esclerito mediano. 

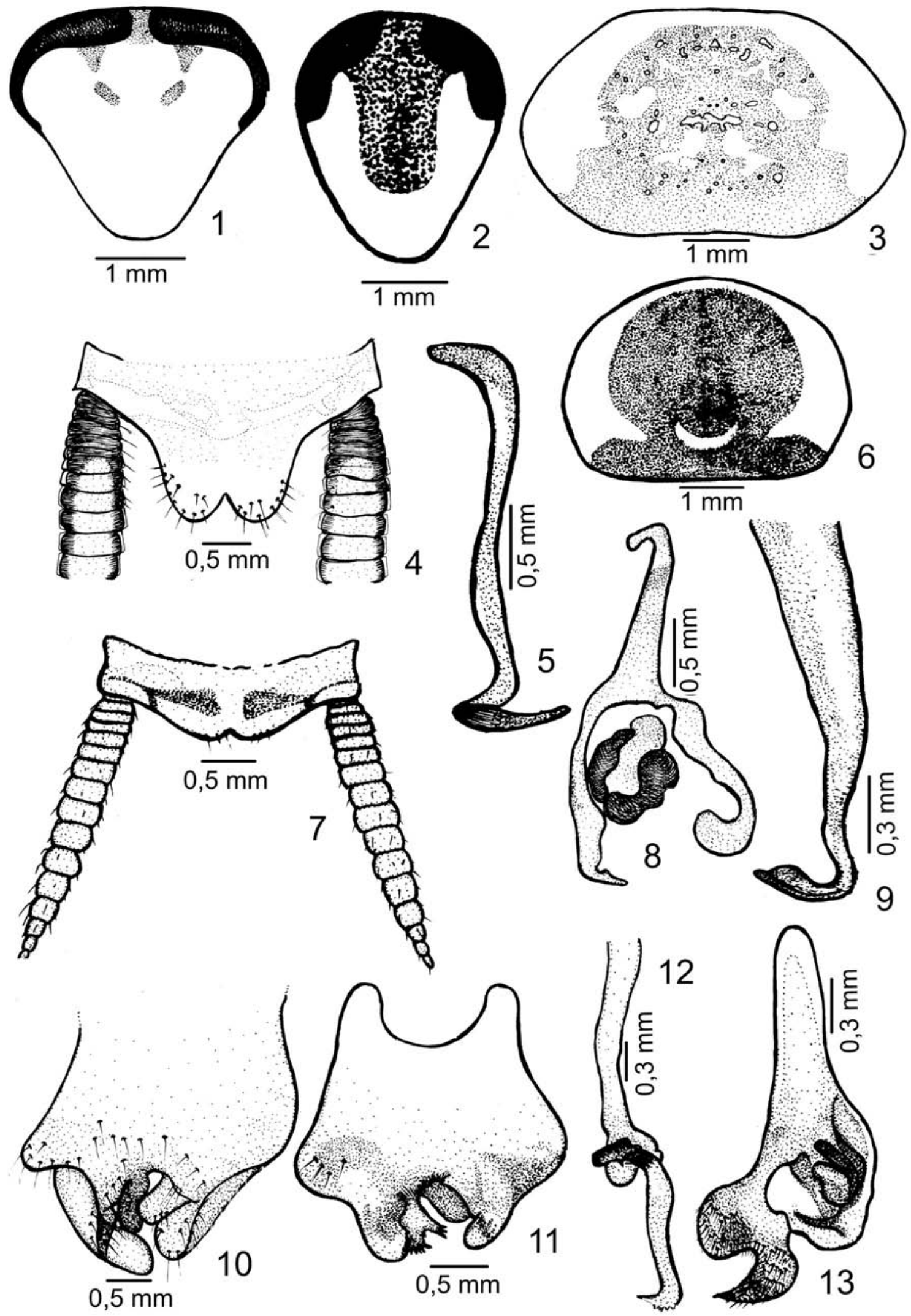

Figs. 1, 3-5, 8, 10. Dendroblatta matogrossensis sp. nov., holótipo ơ: 1, cabeça, ventral; 3, pronoto; 4, placa supra-anal, dorsal; 5, esclerito mediano (L2vm), dorsal; 8, falômero esquerdo (L1), vista dorsal; 10, placa subgenital, ventral; Figs. 2, 6, 7, 9, 11-13. Dendroblatta mineira sp. nov., holótipo o': 2, cabeça, ventral; 6, pronoto; 7, placa supra-anal, dorsal; 9, falômero direito (R2), dorsal; 11, placa subgenital, ventral; 12, esclerito mediano (L2vm), dorsal; 13, falômero esquerdo (L1), dorsal. 


\section{Dendroblatta mineira sp. nov.}

(Figs. 2, 6, 7, 9, 11-13, 15)

Coloração geral castanho-clara (Fig. 15). Cabeça com faixa extensa castanho-escura (Fig. 2), apresentando as antenas com tomentosidade brilhosa, dourada. Pronoto com contorno transparente (Fig. 6). Tégmina com tronco inicial de todas as nervuras e faixa central longitudinal irregular e região dorsal dos fêmures e tíbias castanhoescuros.

Medidas em mm, holótipo ơ. Comprimento total, 17,0; comprimento do pronoto, 3,0; largura do pronoto, 4,5; comprimento da tégmina, 14,5; largura da tégmina, 4,5 .

Cabeça subtriangular (Fig. 2), vértice exposto, espaço interocular estreito com cerca de um quarto da área que separa as bases das inserções antenais; antenas longas, ultrapassam o ápice do abdome; palpos maxilares desenvolvidos, terceiro artículo mais longo que os demais e semelhante em comprimento à área que separa as bases das inserções antenais; quarto artículo dilatado no ápice, quinto dilatado na base, estreitado em direção do ápice, ambos tomentosos.

Pronoto transverso e convexo (Fig. 6), com as margens apical e basal retas, abas laterais amplas, de contorno arredondado. Tégminas longas, ultrapassam o ápice dos cercos; campo marginal bem marcado, curto e abaulado; campo escapular oblíquo e alongado próximo ao terço apical; campo anal pouco desenvolvido e alargado. Pernas desenvolvidas, finas e alongadas. Fêmur anterior apresentando na face ântero-ventral 3 a 5 espinhos maiores até a região mediana, seguidos por uma série cerrada de pequeninos espinhos até próximo ao ápice, mais dois espinhos apicais grandes e robustos; face póstero-ventral com dois espinhos desenvolvidos no terço apical mais um apical robusto; fêmures médio e posterior com espinhação semelhante, apresentando na face ânteroventral seis a sete espinhos robustos desenvolvidos e espaçados, um deles apical; face póstero-ventral com três espinhos robustos, um deles apical. Pulvilos apenas no quarto artículo tarsal, arólio pouco desenvolvido, unhas simétricas e simples.

Abdome sem modificação tergal. Placa supra-anal ciliada, pronunciada entre os cercos, com distinta reentrância mediana; cercos desenvolvidos e ciliados (Fig. 7). Placa subgenital assimétrica, ciliada, com projeções laterais desenvolvidas e arredondadas; estilos alargados e diferenciados na região mediana da placa, um deles bifurcado e o outro arredondado (Fig. 11). Esclerito mediano (L2vm) simples e com ápice (L2d) afilado (Fig. 12). Falômero esquerdo (L1) em forma de Y invertido, com uma das pontas afilada e a região central esclerotinizada (Fig. 13). Falômero direito (R2) em forma de gancho (Fig. 9).

Material-tipo. Holótipo O’, BRASIL, Minas Gerais: Viçosa (Ponte Nova), 18.X.1979, Vanetti col., Planalsucar, 00052; Parátipo O’: mesmos dados do holótipo, 00023.

Etimologia. O nome é alusivo ao estado brasileiro onde o material foi coletado.

Diagnose. Dendroblatta mineira sp. nov. distingue-se das demais espécies do gênero pela configuração dos estilos, que se apresentam diferenciados entre si e pela coloração intensa da cabeça e pronoto.
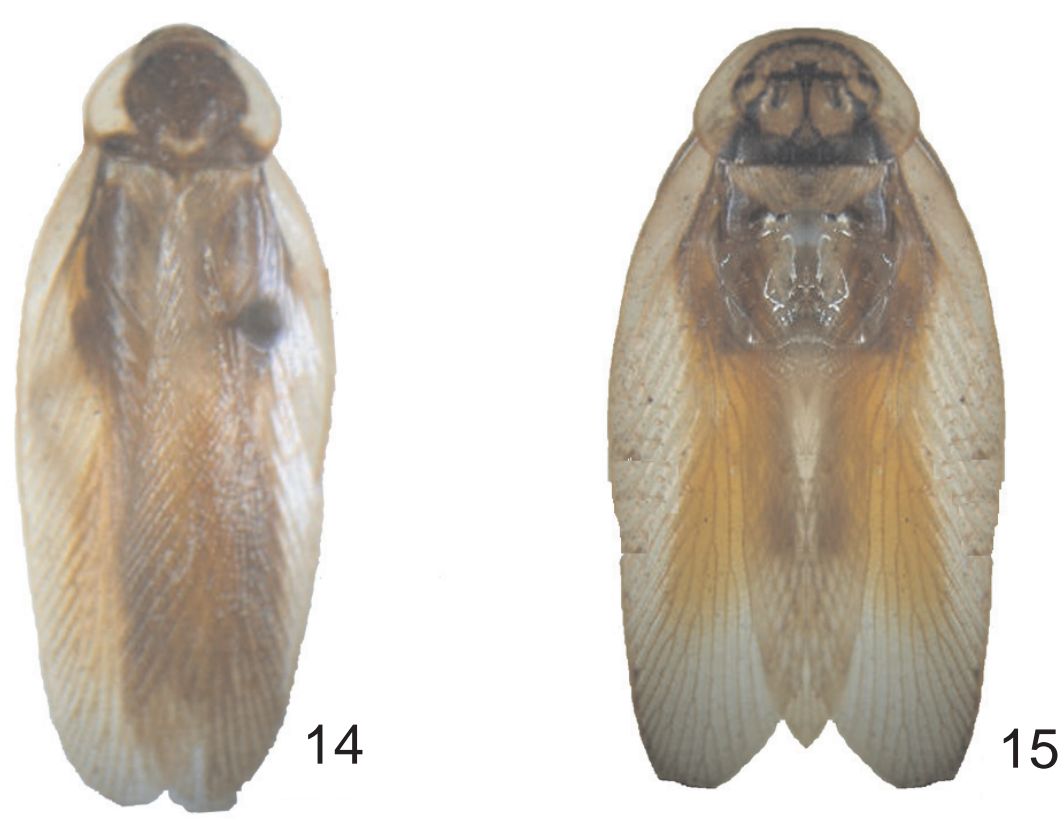

Figs. 14, 15. Habitus: 14, Dendroblatta matogrossensis sp. nov., holótipo $\sigma^{\top}$ (20mm); 15, Dendroblatta mineira sp. nov., holótipo $\sigma^{7}$ $(17 \mathrm{~mm})$. 
Agradecimentos. À Dra. Janira Martins Costa (MNRJ) pelo apoio técnico.

\section{REFERÊNCIAS BIBLIOGRÁFICAS}

Gurney, A. B.; Kramer, J. P. \& Steyskal, G. C. 1964. Some techniques for the preparation, study and storage in microvials of insect genitalia. Annals of the Entomological Society of America 57(2):240-242.
Lopes, S. M. \& Oliveira, E. H. 2000. Material-tipo de Blattaria descritos por Rocha e Silva depositados na coleção do Museu Nacional - Rio de Janeiro. Publicações Avulsas do Museu Nacional 85:1-24.

McKittrick, F. A. 1964. Evolutionary studies of cockroaches. Cornell Experiment Station Memoir 389:1-197.

Rehn, J. A. G. 1916. The Stanford expedition to Brazil, 1911. J. C. Branner, Director. Dermaptera and Orthoptera I. Transactions American Entomological Society 42:215-308. 